\title{
THEORETICAL APPROACH OF DFT B3LYP/6-31G $(d, p)$ ON EVALUATING THE PERFORMANCE OF tert-BUTYLHYDROQUINONE AND FREE FATTY ACIDS IN INHIBITING THE OXIDATION OF PALM OLEIN
}

\section{RADIAH ALI*; KU HALIM KU BULAT**; ALYZA A AZMI* and SABIQAH TUAN ANUAR*}

\begin{abstract}
The effects of adding palmitic acid (PA) and linoleic acid (LA) on the performance of tert-Butylhydroquinone (TBHQ), in inhibiting the autoxidation of palm olein was studied. These fatty acids were employed to test their effectiveness on antioxidant performance, experimentally and theoretically. In experimental studies, palm olein added with fatty acids at four different concentrations in the presence or in the absence of TBHQ were heated in the oven at $60^{\circ} \mathrm{C}$ for 15 days and collected after $0,1,3,6,10$ and 15 days for peroxide values analysis. In the theoretical study, a quantum mechanical at the theoretical level of DFT BSLYP/ 6-31G $(d, p)$ was used in optimising the molecular structures of single species and complexes, and then tested for physical parameters (dipole moment, stabilisation energy, and bond indexes). It was found in the presence of $T B H Q$, synergistic behaviour was found between fatty acid and antioxidants. The addition of $P A$, which is the same as the main component of palm olein, significantly decreased oxidation and peroxide formation, thus gave less effect to the degradation of triacylglycerides. Based on the theoretical calculations, the interaction energy is shown as the major contributor to the performance of the antioxidant.
\end{abstract}

Keywords: autoxidation, theoretical study, TBHQ, palmitic acid, linoleic acid.

Date received: 21 August 2017; Sent for revision: 15 October 2017; Received in final form: 10 October 2018; Accepted: 9 January 2019.

\section{INTRODUCTION}

Lipid autoxidation is an autocatalytic reaction that leads to the development of rancidity. This process, which is the major cause of quality losses in the food industry, could take place during preparation, processing, and storage of food products. Lipid autoxidation and inadequate storage contribute significantly to the deterioration and reduction of

School of Marine and Environmental Sciences,

Universiti Malaysia Terengganu, 21030 Kuala Nerus, Terengganu, Malaysia.

** School of Fundamental Science, Universiti Malaysia Terengganu, 21030 Kuala Nerus, Terengganu, Malaysia.

E-mail: sabiqahanuar@umt.edu.my the shelf-life of vegetable oil, causing changes to appearance, taste, as well as odour, colour, texture, and loss of vitamins (Yang et al., 2016; Milanez and Pontes, 2014; Gallego et al., 2013; Zeb and Murkovic, 2013). Several studies reported that, besides these changes degrade the functional and nutritional compounds of food, they also generate potential toxic compounds through the action of free radicals and reactive oxygen species that are harmful to human health and are implicated in degenerative diseases such as cancer, cardiovascular diseases and early ageing (Difonzo et al., 2018; Womeni et al., 2016). Hence, the susceptibility of food towards lipid oxidation affects the quality of food products and consumer acceptability and limits their applications. 
Autoxidation, which is the most common oxidation phenomenon, occurs through a reaction between the oxygen and fatty acids via an autocatalytic process consisting of a free radical chain mechanism. This type of chain includes initiation, propagation, and termination processes, which could be cycled once started (Taghvaei et al., 2014). Autoxidation radical chain reactions are the primary cause of oil degradation that leads to the formation of hydroperoxides, which continuously undergo decomposition to form an array of secondary oxidation products such as aldehydes, ketones, and carboxylic acids (Mohanan et al., 2018). The degradation process of vegetable oils not only involves oxidation but also cis-trans isomerisation and free fatty acid (FFA) production.

According to Sainsbury et al. (2016) and Paradiso et al. (2010), vegetable oil oxidation is affected by many factors such as the presence of antioxidants (inhibitors) or pro-oxidants (catalysts), temperature, light, oxygen, metals, and enzymes (regarding processing and storage conditions), as well as unsaturated fatty acids composition and their distribution in triacylglyceride (TAG) molecules.

Palm olein, relatively an inexpensive vegetable oil, is widely consumed as a major lipid source in developing countries. Malaysia and Indonesia are the leading countries which export palm oil around $86 \%$ of global production (Damanik and Murkovic, 2018). Palm olein is the preferred oil for cooking and frying because it has good oxidative stability. Refined, bleached, and deodourised (RBD) palm olein contains high amounts of palmitic acid (PA) $(\sim 43 \%)$, oleic acid $(\sim 41 \%)$, and linoleic acid (LA) ( 10\%) (Pillai et al., 2016). Palm olein has a balanced fatty acid composition in which the level of saturated fatty acid is almost equal to that of the unsaturated fatty acid (Table 1). One of the unique characteristics of palm olein is its high content of carotenoids and vitamin E. Natural tocopherol, especially $\alpha$-tocopherol, is a superior radical chainbreaking antioxidant as compared to the synthetic ones. The presence of this natural vitamin $\mathrm{E}$ in palm olein ensures a longer shelf-life for the palm-based food products (Damanik and Murkovic, 2018).

TABLE 1. FATTY ACID COMPOSITION OF PALM OLEIN

\begin{tabular}{lcc}
\hline Name & Structure & Composition (wt \%) \\
\hline Lauric & $12: 0$ & $0.1-1.0$ \\
Myristic & $14: 0$ & $0.9-1.5$ \\
Palmitic & $16: 0$ & $41.8-46.8$ \\
Palmitoleic & $16: 1$ & $0.1-0.3$ \\
Stearic & $18: 0$ & $4.2-5.1$ \\
Oleic & $18: 1$ & $37.3-40.8$ \\
Linoleic & $18: 2$ & $9.1-11.0$ \\
Linolenic & $18: 3$ & $0-0.6$ \\
Arachidic & $20: 0$ & $0-0.7$ \\
\hline
\end{tabular}

A number of works have been reported on the effects of antioxidants and FFA separately, specifically on the oxidative stability of edible oils during processing and storage. However, most of the previous research studies involved only experimental works, and the analyses of oils degradation were carried out either conventionally by peroxide value and acid number (Yu et al., 2015), or by analytical means such as Fourier transform infrared (FTIR) spectrometry (Yu et al., 2015; Xu et al., 2016; Tena et al., 2017; Cozzolino, 2015), gas chromatography (Hayward et al., 2014) or mass spectrometry (Bataglion et al., 2014; Cabral et al., 2013), where the available information is insufficient in determining the main physical parameters in affecting the oil oxidation and stability. The literature also reveals that up to the present date, there are limited reports regarding the experimental or theoretical studies that have been carried out on the performance of antioxidants in inhibiting the autoxidation of palm oil in the presence of different compositions of fatty acid. Recently, the current researchers have reported the synergistic effects of some fatty acids on the performance of synthetic antioxidant in inhibiting the oxidation of TAG of corn oil, where they found that the addition of polyunsaturated fatty acids theoretically will decrease the corn oil degradations (Ali et al., 2017).

Therefore, the aim of this research was to study, both theoretically and experimentally, the performance of tert-Butylhydroquinone (TBHQ) antioxidant towards the oxidative stability of palm olein, which is known to have more saturated fatty acids in the TAG constituent, whether in the presence or absence of additional fatty acids. These experimental results were compared with the theoretical calculations using the quantum mechanical software package of Gaussian09. In particular, the theoretical level of B3LYP/6-31G $(d, p)$ was used for the optimisation and evaluation of physical properties such as stabilisation energy, dipole moment, bond index, and any other physical properties that might be responsible for the interaction between peroxide radical and antioxidants in the presence or absence of fatty acids. To our knowledge, this study was the first reported finding on the theoretical calculations of physical properties for the determination of palm olein stability, which can be both valuable to the other researchers and palm oil industry.

\section{MATERIALS AND METHODS}

\section{Theoretical Studies}

The molecular structure drawings were done with GaussView 5.0 (Dennington et al., 2009) 
molecular visualisation program package. A modification of density functional theory (DFT) at hybrid functional B3LYP with 6-31G $(\mathrm{d}, \mathrm{p})$ basis sets was employed for the study of physical interaction between methyl oleate radical $\left(\mathrm{MO} \mathrm{C}_{8} \mathrm{OO}^{\bullet}\right)$ with antioxidants, $\mathrm{MO} \mathrm{C}_{8} \mathrm{OO}{ }^{\bullet}$ with fatty acids, and $\mathrm{MO} \mathrm{C}_{8} \mathrm{OO}^{\bullet}$ with antioxidants and fatty acids during the oxidation processes (Ali et al., 2017). The $\mathrm{MO} \mathrm{C}_{8} \mathrm{OO}^{\bullet}$ was used as a molecular model to represent palm olein. All calculations were carried out by using Gaussian09 (Frisch et al., 2009). Optimised geometries were obtained by gradient minimisation using the DFT method without any symmetry constraint.

\section{Experimental Studies}

Chemicals. RBD palm olein was purchased from the local grocery store. TBHQ and fatty acids: PA and LA were supplied by Merck and used without any further purification. Merck also supplied chemicals and other solvents used for analyses such as glacial acetic acid, chloroform, potassium iodide, and sodium thiosulphate.

Preparation of samples. Palm olein was mixed with fatty acids at four different combinations: $0.25 \%, 0.5 \%, 1.0 \%$, and $3.0 \% \mathrm{w} / \mathrm{w}$ in the presence or absence of $0.5 \%$ TBHQ. The samples of palm olein alone and mixtures (antioxidants and fatty acids) were continuously heated in the oven at $60^{\circ} \mathrm{C}$ for 15 days under an oxygen atmosphere. Samples of oil for analyses were taken after the samples were heated at $60^{\circ} \mathrm{C}$. The samples of oil were collected at Day $0,1,3,6,10$, and 15 for routine analyses. All of the samples collected were analysed for peroxide value.

Peroxide value. Peroxide value is a measure of the concentration of peroxides and hydroperoxides formed in the initial state, and the results are expressed as meq $\mathrm{kg}^{-1}$ oil (Farhoosh et al., 2016). The peroxide value was estimated iodometrically using sodium thiosulphate according to the AOCS Official Method Cd 8-53 acetic acid - chloroform method (AOCS, 1993).

\section{RESULTS AND DISCUSSION}

Peroxide value is an index for peroxide and hydroperoxides measurement produced in the initial stages of lipid oxidation. As stated by Farhoosh et al. (2016), peroxide value is one of the most widely used methods for oils oxidative rancidity evaluation. In this research, the oxidation of palm olein was determined by measuring the peroxide value at $60^{\circ} \mathrm{C}$ for 15 days. One day at $60^{\circ} \mathrm{C}$ is equivalent to one month's storage at ambient temperature (Warner et al., 1989). Figure 1 shows the reaction for peroxide value determination.

In accordance with the results, it was found that the peroxide value increased with the storage time of palm olein. Figure 2 for all palm olein samples show that there was a slow increment during the first 10 days and a sudden increase after that. The palm olein samples reached the highest peroxide value of 22.0 meq kg-1 after 15 days of exposure. However, the addition of TBHQ $0.5 \%$ reduced the peroxide value to $18 \mathrm{meq} \mathrm{kg}^{-1}$. The antioxidant retarded the deterioration process due to oxidation.

The peroxide value of palm olein containing TBHQ $0.5 \%$ (symbol: $\mathbf{})$ was lower than palm olein alone (symbol: $\bullet$ ) (Figures 2 and 3). The addition of $0.5 \% \mathrm{w} / \mathrm{w}$ TBHQ effectively acted as an antioxidant in inhibiting oxidation (Pimpa et al., 2009), where the peroxide value decreased as compared to palm olein alone. The peroxide value increased proportionally with the day of exposure.

The addition of free fatty acids, PA and LA at different concentrations, $0.25 \%, 0.5 \%, 1.0 \%$, and $3.0 \%$ $\mathrm{w} / \mathrm{w}$ into combination of palm olein and TBHQ $0.5 \%$ significantly changed the oxidation stability of palm olein (Figures 2 and 3; symbols: $\boldsymbol{\Lambda},+, \bullet$ and $\times$, respectively). The initial values of peroxide for palm olein and combination with fatty acids are the same at $4.0 \mathrm{meq} \mathrm{kg}^{-1}$. The influence of fatty acids during storage on oxidative stability of palm olein is shown in Figures 2 and 3. Results showed that the peroxide value increased linearly with the days of exposure. The addition of less than $1.0 \% \mathrm{w} / \mathrm{w}$ PA decreased the peroxide value of palm olein due to the reduction of hydroperoxide formation (Figure 2). It means that lower amount of saturated fatty acid (i.e. PA is able to inhibit the oxidation process and increase the storage life of palm olein) (Paradiso et al., 2010).

In contrast, the addition of more than $1.0 \% \mathrm{w} / \mathrm{w}$ PA enhanced the oxidation of palm olein. Previously, Colakoglu (2007) found that the addition of $1 \%$ of saturated acid to oil caused an increase in peroxide formation. The result obtained showed that the peroxide value increased proportionally with the day of exposure. The results of this study showed that the presence of up to $1.0 \% \mathrm{w} / \mathrm{w}$ PA reduced the formation of the peroxides. As shown in Figure 2, the

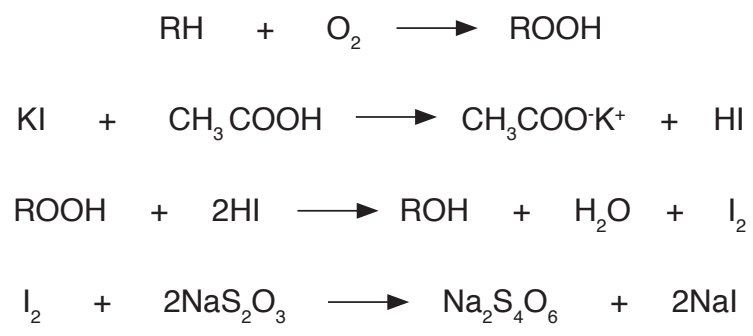

Figure 1. Reaction for peroxide value determination. 


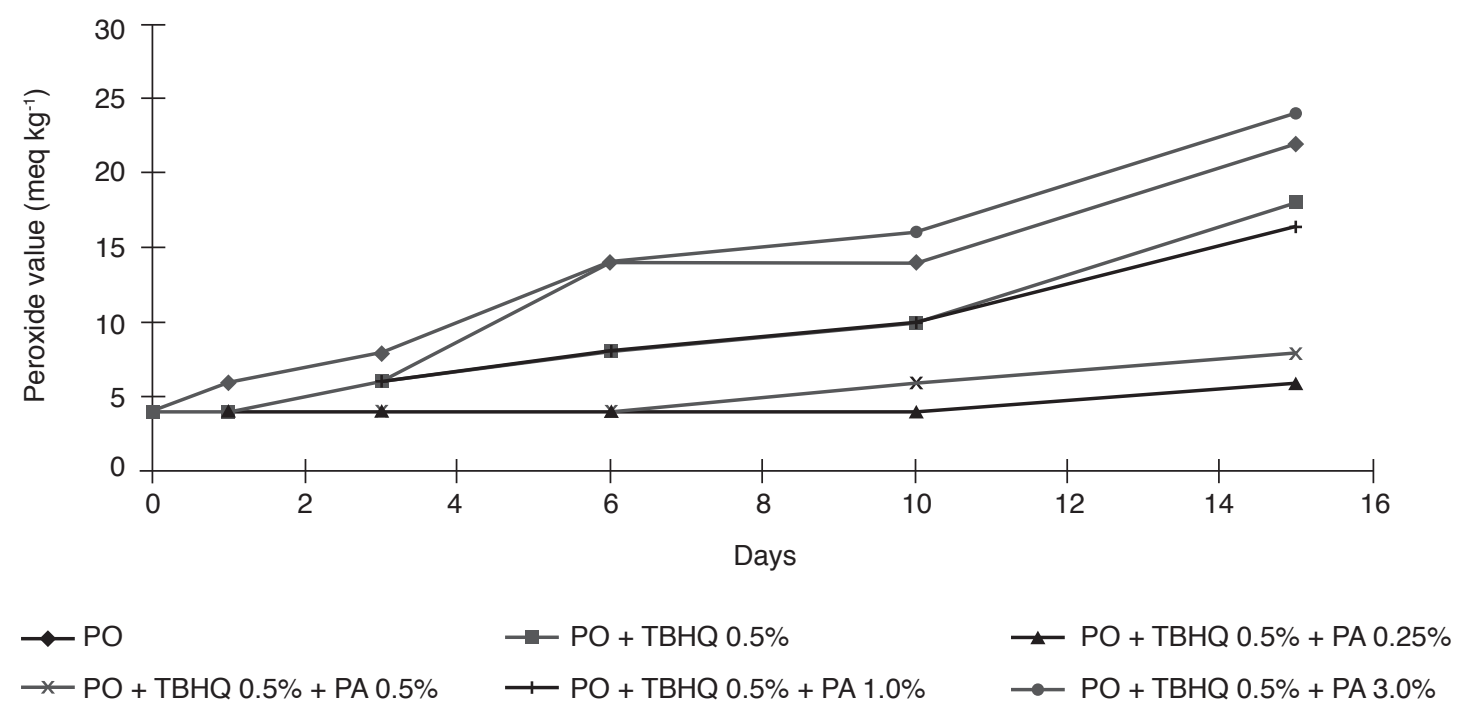

Figure 2. Peroxide value of palm olein with added tert-Butylhydrolquinone (TBHQ) $0.5 \%$ and palmitic acid (PA).

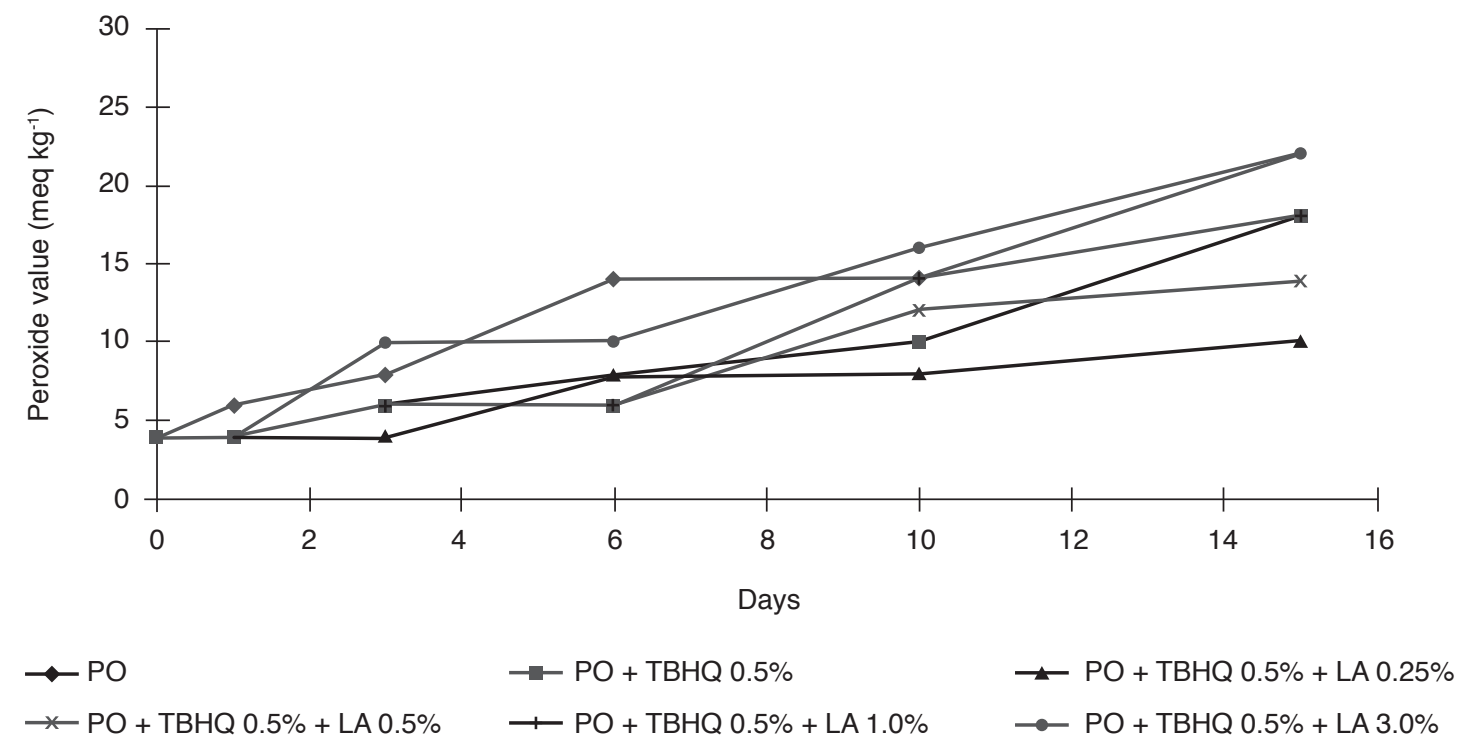

Figure 3. Peroxide value of palm olein with added tert-Butylhydrolquinone (TBHQ) $0.5 \%$ and linoleic acid (LA).

combination of TBHQ with PA shows the synergistic effect in reducing the peroxide group formation. The order of the performance of antioxidants in inhibiting the oxidation of palm olein is as follows: $\mathrm{PO}+\mathrm{TBHQ} 0.5 \%+\mathrm{PA} 0.25 \%>\mathrm{PO}+\mathrm{TBHQ} 0.5 \%+$ $\mathrm{PA} 0.5 \%>\mathrm{PO}+\mathrm{TBHQ} 0.5 \%+\mathrm{PA} 1.0 \%>\mathrm{PO}+\mathrm{TBHQ}$ $0.5 \%>\mathrm{PO}$ alone $>\mathrm{PO}+\mathrm{TBHQ} 0.5 \%+\mathrm{PA} 3.0 \%$.

The addition of TBHQ $0.5 \%$ and PA shows the synergistic effect where the peroxide value of the palm olein decreased. The combination of TBHQ $0.5 \%$ and PA $0.25 \%$ improved the oxidative stability of palm olein from $20 \mathrm{meq} \mathrm{kg}^{-1}$ to 6 meq $\mathrm{kg}^{-1}$; combination of TBHQ $0.5 \%$ and PA $0.5 \%$ reduced from 20 meq $\mathrm{kg}^{-1}$ to $8 \mathrm{meq} \mathrm{kg}$. The same phenomenon occurred to TBHQ $0.5 \%$ and PA $1.0 \%$ where it reduced from $26 \mathrm{meq} \mathrm{kg}^{-1}$ to $16 \mathrm{meq} \mathrm{kg}^{-1}$ while peroxide value of combination TBHQ $0.5 \%$ and PA $3.0 \%$ decreased from $26 \mathrm{meq} \mathrm{kg}^{-1}$ to $24 \mathrm{meq}$ $\mathrm{kg}^{-1}$.

Previous studies on the theoretical evaluation of corn oil oxidation (Ali et al., 2017) found that the combination of fatty acid, antioxidant, and hydroperoxyl radical (methyl linoleate $\mathrm{C}_{9} \mathrm{OO}^{*}$ ) formed a stable complex and the interaction energy showed the major contribution. In the present study, $\mathrm{MO} \mathrm{C}_{8} \mathrm{OO}^{*}$ which is one of the TAG chains was used as a molecular model to represent the palm olein, since there are limitations in using the whole TAG 
structure of vegetable oil for the complex molecular drawing (Che Othman, 2015). An initial study by the current researchers showed that the $\mathrm{MO} \mathrm{C}_{8} \mathrm{OO}^{\circ}$ was the reactive chain and susceptible to the interaction with the antioxidant and additional free fatty acid. Nevertheless, the present study found that the molecular model used was effective in representing palm olein and in agreement with the experimental findings by peroxide values. After the optimisation, the dipole moment showed that TBHQ was compatible with $\mathrm{MO}[\mu \mathrm{TBHQ}=2.2789 \mathrm{D} ; \mu \mathrm{MO}=2.5974 \mathrm{D}]$. It indicates that TBHQ is effective in inhibiting the autoxidation of palm olein.

As reported by Shahidi and Ambigaipalan (2015), antioxidants such as TBHQ provide more active sites for the development of a complex between the free radical of the sample and the antioxidants. This was proven by the findings of the current study where TBHQ will provide two sites of $\mathrm{O}-\mathrm{H}$ functionality for the antioxidant reaction with the oil; however, only $\mathrm{O}-\mathrm{H}$ (1) will interact in the reaction (Figure 4).

Moreover, it was found that the bond index of $\mathrm{O}-\mathrm{H}$ for the TBHQ was significantly lower (0.7388) than the bond index of $\mathrm{O}-\mathrm{H}$ hydroperoxide for $\mathrm{MO} \mathrm{C}_{8} \mathrm{OOH}$ (oil) (0.7580) as shown in Table 2. This theoretical calculation showed that TBHQ easily donated the $\mathrm{H}$ radical to hydroperoxyl/radicals

\begin{tabular}{lccc}
\multicolumn{3}{c}{$\begin{array}{c}\text { TABLE 2. PHYSICAL PROPERTIES OF METHYL OLEATE/ } \\
\text { HYDROPEROXYL RADICALS AND ANTIOXIDANT }\end{array}$} \\
$\begin{array}{l}\text { Dipole } \\
\text { moment }\end{array}$ & $\begin{array}{c}\text { Bond index } \\
\left.\mathbf{( I}_{\mathrm{O}-\mathrm{H}}, \AA\right)\end{array}$ & $\begin{array}{c}\text { Bond } \\
\text { distance, } \\
\left(\mathbf{r}_{\mathrm{O}-\mathrm{H},}, \AA\right)\end{array}$ \\
\hline $\begin{array}{l}\text { Methyl oleate } \mathrm{C}_{8} \mathrm{OOH} \\
\text { Methyl oleate } \mathrm{C}_{8} \mathrm{OO}\end{array}$ & 1.6880 & 0.7580 & 0.97367 \\
TBHQ & 2.2789 & - & - \\
\hline
\end{tabular}

Note: TBHQ - tert-Butylhydroquinone.
$\mathrm{COO}^{\bullet}$ likewise the methyl oleate. From the bond index analyses, it also showed that antioxidant had similar performance with the FFA to donate their $\mathrm{H}$ radical. This result was in line with the experimental results published elsewhere (Ali et al., 2017).

Meanwhile, Figure 3 shows the effect of more unsaturated free fatty acids (LA) on the performance of TBHQ $0.5 \% \mathrm{w} / \mathrm{w}$ on the peroxide value of palm olein. The addition of TBHQ $0.5 \% \mathrm{w} / \mathrm{w}$ and LA at the concentration of up to $0.5 \% \mathrm{w} / \mathrm{w}$, gave synergistic effect and helped reduce the peroxide value of palm olein. Surprisingly, the usage of LA in palm olein at the concentration of more than $0.5 \% \mathrm{w} / \mathrm{w}$ displayed an antagonistic effect (Figure 3, symbol: $+)$. The presence of high levels of polyunsaturated fatty acids in the vegetable oil severely reduces the benefit of any added antioxidants (Ali et al., 2017).

The oxidation of palm olein is directly proportional to the quantity of LA added. This indicates that LA acts as a pro-oxidant, where the addition of $3.0 \%$ LA shoots to the highest peroxide value of $38.0 \mathrm{meq} \mathrm{kg}$. However, the addition of TBHQ $0.5 \%$ reduced the peroxide value of palm olein as shown in Figure 3. This show that TBHQ 0.5\% and LA acted synergistically in reducing the oxidation. The order of the performance of antioxidants in inhibiting the oxidation of palm olein is as follows: $\mathrm{PO}+\mathrm{TBHQ} 0.5 \%+\mathrm{LA} 0.25 \%\left(\mathrm{PV}=10 \mathrm{meq} \mathrm{kg}{ }^{-1}\right)>\mathrm{PO}$ + TBHQ $0.5 \%+$ LA $0.5 \%\left(P V=14\right.$ meq $\left.\mathrm{kg}^{-1}\right)>\mathrm{PO}+$ TBHQ $0.5 \%+$ LA $1.0 \%=$ PO + TBHQ 0.5\% (PV=18 meq $\mathrm{kg}^{-1}$ ) $>$ PO alone $=\mathrm{PO}+\mathrm{TBHQ} 0.5 \%+\mathrm{LA} 3.0 \%$ $\left(\mathrm{PV}=22 \mathrm{meq} \mathrm{kg}^{-1}\right)$.

The present finding shows that the fatty acid composition of the oil will affect the behaviour of FFA whether it is synergistic or antagonistic (prooxidant) for the systems. Previously, the current researchers reported that the LA addition to the corn oil that contains around $65 \%-70 \%$ of unsaturated fatty acids helped in reducing the oxidation of the

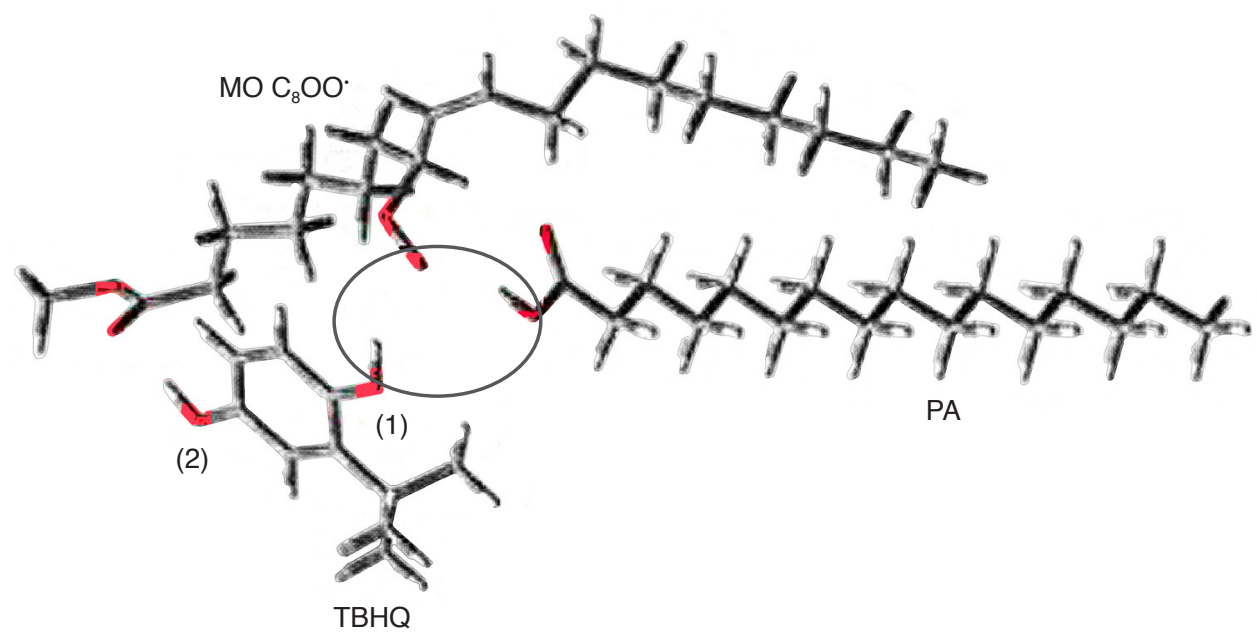

Figure 4. Molecular structure on the interaction between methyl oleate with antioxidant $\left(\mathrm{MO}_{8} \mathrm{OO}^{\bullet}\right)$, tert-Butylhydrolquinone (TBHQ) and palmitic acid (PA). 
corn oil (Ali et al., 2017), meanwhile in this study, it was found that the addition of PA, instead of LA, helped in promoting the antioxidation of palm olein. Figure 5 shows the molecular structure of the interaction between LA, TBHQ, and palm olein.

Theoretically, the bond dissociation energies influence the effectiveness of hydrogen atom transfer reaction from the antioxidant molecules to the reactive radical intermediates such as hydroxyl, alkoxyl, peroxyl, and hydroperoxyl radicals formed during the degradation reactions. The antioxidants' bond dissociation energies would have to be lower than the peroxyl radical and hydroperoxyl radicals to efficiently quench all destructive radical intermediates (Mohanan et al., 2018). The total electron and interaction energies are tabulated in Table 3. The complex with TBHQ in the presence of PA formed a more stable complex with $\mathrm{C}_{8} \mathrm{OO}{ }^{\bullet}$ and TBHQ as compared to LA, where the stabilisation energy with PA was $-85.32 \mathrm{~kJ} \mathrm{~mol}^{-1}$ and complex with LA was $-74.24 \mathrm{~kJ} \mathrm{~mol}^{-1}$. The details of the analyses showed that the addition of PA improved the interaction of the tri-species system by $-0.63 \mathrm{~kJ}$ $\mathrm{mol}^{-1}$ (from -84.69 to $-85.32 \mathrm{~kJ} \mathrm{~mol}^{-1}$ ). In contrast, the addition of LA to the complex decreased the stabilisation energy in the system by $+3.01 \mathrm{~kJ} \mathrm{~mol}^{-1}$, which was from $-77.25 \mathrm{~kJ} \mathrm{~mol}^{-1}$ to $-74.24 \mathrm{~kJ} \mathrm{~mol}^{-1}$. Based on these theoretical findings, it can be proven that the addition of PA to TBHQ will reduce the peroxide value of palm olein as compared to LA, experimentally.

\section{CONCLUSION}

A theoretical approach to measure the oil oxidation is reported here. In summary, whether the system of tri-species $\left(\mathrm{C}_{8} \mathrm{OO}^{\bullet}+\right.$ antioxidant + FFA $)$ will be affected or not with the presence of free fatty acids is dependent upon the total interaction energy of the tri-species involved in the system. The synergistic behaviour between both antioxidant and fatty acid in the system will contribute to the decrease of peroxide value for the oil, while the antagonistic behaviour between the species will promote the oxidation of the oil. Furthermore, the addition of fatty acids (saturated or polyunsaturated) at certain concentrations, especially at low concentrations, is able to improve the performance of antioxidants through the formation of synergistic tri-species complexes. It is also worth to note that in the presence of TBHQ, saturated fatty acids such as PA show a better synergistic effect as compared to more unsaturated ones (LA) in reducing the oxidation of palm olein. It can be concluded that the proposed method of using optimised molecular model DFT B3LYP / 6-31G (d,p), make this method ideal for the measurement of factor affecting the oil oxidation. Results from the optimised theoretical calculation also showed that the complexity of the oil in terms of $\mathrm{C}_{8} \mathrm{OO}^{\bullet}$ with TBHQ and PA has a higher interaction energy than the complex with LA, thus giving merits to the usage of PA in this system. However, for the future works in theoretical studies, the optimisation on the real triacylglycerols TAG composition of the palm olein (such as POP, POO, POL etc.), instead of using only one chain of TAG, could be suggested in order to improve the interaction properties.

TABLE 3. TOTAL ELECTRONIC ENERGY AND INTERACTION ENERGY

\begin{tabular}{|c|c|c|}
\hline System & $\begin{array}{l}\text { SCF energy } \\
\text { (a.u) }\end{array}$ & $\begin{array}{c}\text { Interaction } \\
\text { energy }\left(\mathrm{kJ} \mathrm{mol}^{-1}\right)\end{array}$ \\
\hline $\mathrm{C}_{8} \mathrm{OO}^{\bullet}+\mathrm{TBHQ}+\mathrm{PA}$ & -2365.448282 & -85.3163 \\
\hline $\mathrm{C}_{8} \mathrm{OO}^{\bullet}+\mathrm{TBHQ}$ & -1585.908801 & -44.2752 \\
\hline $\mathrm{C}_{8} \mathrm{OO}^{\bullet}+\mathrm{PA}$ & -1825.465358 & -25.2360 \\
\hline $\mathrm{TBHQ}+\mathrm{PA}$ & - & -84.6891 \\
\hline $\mathrm{C}_{8} \mathrm{OO}^{\bullet}+\mathrm{TBHQ}+\mathrm{LA}$ & -2441.604613 & -74.2389 \\
\hline $\mathrm{C}_{8} \mathrm{OO}^{\bullet}+\mathrm{TBHQ}$ & -1585.908949 & -44.6641 \\
\hline $\mathrm{C}_{8} \mathrm{OO}^{\bullet}+\mathrm{LA}$ & -1901.621763 & -14.3522 \\
\hline TBHQ + LA & - & -77.2489 \\
\hline
\end{tabular}

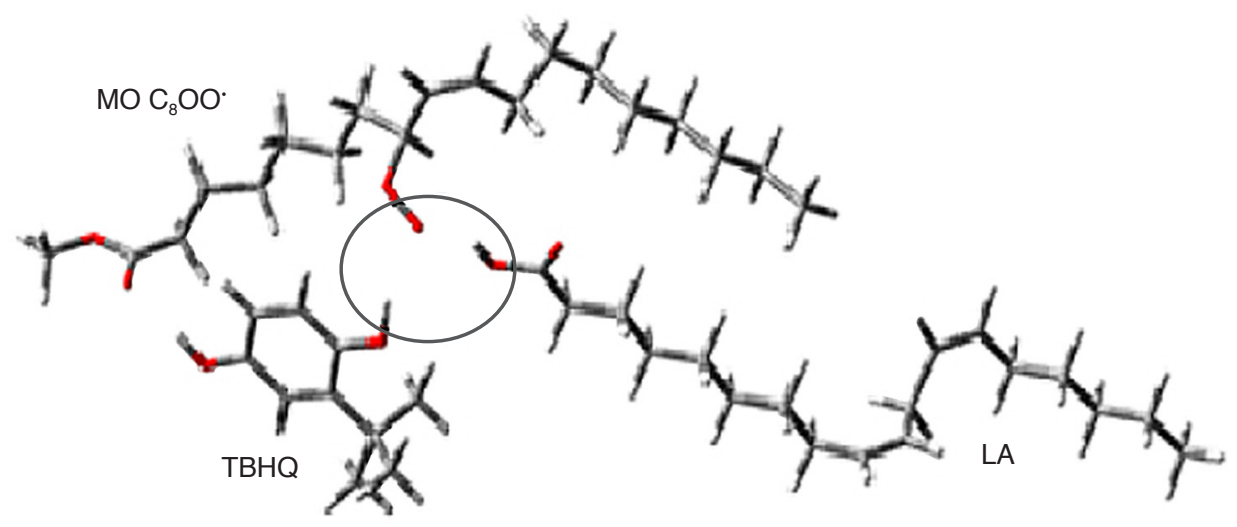

Figure 5. Molecular structure on the interaction between methyl oleate with antioxidant $\left(\mathrm{MO} \mathrm{C}_{8} \mathrm{OO} \mathrm{O}^{\bullet}\right.$ ), tert-Butylhydrolquinone (TBHQ) and linoleic acid (LA). 


\section{ACKNOWLEDGEMENT}

The authors would like to acknowledge the Ministry of Education, Malaysia for the research fund on grants of FRGS 59249 and 59327. We would also like to gratefully acknowledge the MyBrain15 (MyMaster) grant from the Malaysian Ministry of Higher Education for supporting the graduate student for this work. Additionally, many thanks to the Organic Chemistry Laboratory, School of Fundamental Science and Central Laboratory, Universiti Malaysia Terengganu for the assistance in completing this work.

\section{REFERENCES}

Ali, R; Ku Bulat, K; Azmi, A A and Anuar, S T (2017). Synergistic effects of fatty acids on the performance of TBHQ in inhibiting the oxidation of corn oil. J. Scientific Research and Development, 4: 1-5.

AOCS (1993). AOCS Official Method Cd 8-53: Peroxide value: Acetic acid-chloroform method. Official Methods and Recommended Practices of the American Oil Chemists' Society.

Bataglion, G A; Da Silva, F M A; Santos, J M; Dos Santos, F N; Barcia, M T; De Lourenco, C C; Salvador, M J; Godoy, H T; Eberlin, M $\mathrm{N}$ and Koolen, H H F (2014). Comprehensive characterization of lipids from Amazonian vegetable oils by mass spectrometry techniques. Food Research International, 64: 472-481.

Cabral, E C; Da Cruz, G F; Simas, R C; Sanvido, G B; De V Gonçalves, L; Leal, R V P; Da Silva, R C F; Da Silva, J C T; Barata, L E S; Da Cunha, V S; De Franca, L F; Daroda, R J; Desa, G F and Eberlin, M N (2013). Typification and quality control of the andiroba (Carapa guianensis) oil via mass spectrometry fingerprinting. Analytical Methods, 5(6): 1385-1391.

Che Othman, S B (2015). Experimental and Theoretical Studies on the Effects of Fatty Acids on the Performance of Antioxidants Inhibiting the Oxidation of Selected Vegetable Oils. Ph.D thesis. Universiti Malaysia Terengganu, Malaysia.

Colakoglu, A (2007). Oxidation kinetics of soyabean oil in the presence of monoolein stearic acid and iron. Food Chemistry, 101(2): 724-728.

Cozzolino, D (2015). The role of vibrational spectroscopy as a tool to assess economically motivated fraud and counterfeit issues in agricultural products and foods. Analytical Methods, 7(22): 9390-9400.
Damanik, M and Murkovic, M (2018). The stability of palm oils during heating in a rancimat. European Food Research and Technology, 244: 1293-1299.

Dennington, R; Keith, T and Millam, J (2009). GaussView. Version 5, Semichem Inc., Shawnee Mission KS.

Difonzo, G; Pasqualone, A; SillettI, R; Cosmai, L; Summo, C; Paradiso, V M and Caponio, F (2018). Use of olive leaf extract to reduce lipid oxidation of baked snacks. Food Research International, 108: 48-56.

Farhoosh, R; Johnny, S; Asnaashari, M; Molaahmadibahraseman, N and Sharif, A (2016). Structure-antioxidant activity relationships of O-hydroxyl, O-methoxy, and alkyl ester derivatives of p-hydroxybenzoic acid. Food Chemistry, 194: 128134

Frisch, M J; Trucks, G W; Schlegel, H B; Scuseria, G E; Robb, M A; Cheeseman, J R; Scalmani, G; Barone, V; Mennucci, B; Petersson, G A; Nakatsuji, H; Caricato, M; LI, X; Hratchian, H P; Izmaylov, A F; Bloino, J; Zheng, G; Sonnenberg, J L; Hada, M; Ehara, M; Toyota, K; Fukuda, R; Hasegawa, J; Ishida, M; Nakajima, T; Honda, Y; Kitao, O; Nakai, H; Vreven, T; Montgomery, J A; Peralta Jr, J E; Ogliaro, F; Bearpark, M; Heyd, J J; Brothers, E; Kudin, K $\mathrm{N}$; Staroverov, V N; Kobayashi, R; Normand, J; Raghavachari, K; Rendell, A; Burant, J C; Iyengar, S S; Tomasi, J; Cossi, M; Rega, N; Millam, M J; Klene, M; Knox, J E; Cross, J B; Bakken, V; Adamo, C; Jaramillo, J; Gomperts, R; Stratmann, R E; Yazyev, O; Austin, A J; Cammi, R; Pomelli, C; Ochterski, J W; Martin, R L; Morokuma, K; Zakrzewski, V G; Voth, G A; Salvador, P; Dannenberg, J J; Dapprich, S; Daniels, A D; Farkas, Ö; Foresman, J B; Ortiz, J V; Cioslowski, J and Fox, D J (2009). Gaussian 09. Revision D.01. Gaussian, Inc., Wallingford CT.

Gallego, M G; Gordon, M; Segovia, F; Skowyra, M and Almajano, M (2013). Antioxidant properties of three aromatic herbs (rosemary, thyme and lavender) in oil-in-water emulsions. J. Amer. Oil Chem. Soc., 90 (10): 1559-1568.

Hayward, T; Gras, R and Luong, J (2014). Characterization of selected oxidation inhibitors in transformer oils by multidimensional gas chromatography with capillary flow technology. Analytical Methods, 6(20): 8136-8140.

Milanez, K D T M and Pontes, M J C (2014). Classification of edible vegetable oil using digital image and pattern recognition techniques. Microchemical J., 113: 10-16.

Mohanan, A; Nickerson, $\mathrm{M}$ T and Ghosh, S (2018). Oxidative stability of flaxseed oil: Effect of 
hydrophilic, hydrophobic and intermediate polarity antioxidants. Food Chemistry, 266: 524-533.

Paradiso, V M; Gomes, T; Nasti, R; Caponio, F and Summo, C (2010). Effects of free fatty acids on the oxidative processes in purified olive oil. Food Research International, 43(5): 1389-1394.

Pillai, P K S; Li, S; Bouzidi, L and Narine, S S (2016). Metathesized palm oil \& novel polyol derivatives: Structure, chemical composition and physical properties. Industrial Crops and Products, 84: 205-223.

Pimpa, B; Kanjanasopa, D and Boonlam, S (2009). Effect of addition of antioxidants on the oxidative stability of refined bleached and deodorized palm olein. Kasetsart J. (Nat. Sci), 43: 370-377.

Sainsbury, J; Grypa, R; Ellingworth, J; Duodu, K G and De Kock, H L (2016). The effects of antioxidants and shelf life conditions on oxidation markers in a sunflower oil salad dressing emulsion (SOSDE). Food Chemistry, 213: 230-237.

Shahidi, F and Ambigaipalan, P (2015). Phenolics and polyphenolics in foods, beverages and spices: Antioxidant activity and health effects - A review. J. Functional Foods, 18: 820-897.

Taghvaei, M; Jafari, S M; Mahoonak, A S; Nikoo, A M; Rahmanian, N; Hajitabar, J and Meshginfar, N (2014). The effect of natural antioxidants extracted from plant and animal resources on the oxidative stability of soybean oil. LWT-Food Science and Technology, 56 (1): 124-130.
Tena, N; Aparicio, R and García-González, D L (2017). Virgin olive oil stability study by mesh CellFTIR spectroscopy. Talanta, 167: 453-461.

Warner, K; FRankel, E N and Mounts, T L (1989). Flavor and oxidative stability of soybean, sunflower and low erucic acid rapeseed oils. J. Amer. Oil Chem. Soc., 66(4): 558-564.

Womeni, H M; Djikeng, F T; Anjaneyulu, B; Karuna, MS L; Prasad, R B N and Linder, M (2016). Oxidative stabilization of RBD palm olein under forced storage conditions by old Cameroonian green tea leaves methalonic extract. NFS J., 3: 33-40.

Xu, L; Yu, X; Liu, L and Zhang, R (2016). A rapid method for evaluating the edible oil oxidative stability during ambient storage by FTIR spectroscopy using a mesh cell. Analytical Methods, 8(25): 5117-5122.

Yang, Y; Song, X; Sui, X; Qi, B; Wang, Z; Li, Y and Jiang, L (2016). Rosemary extract can be used as a synthetic antioxidant to improve vegetable oil oxidative stability. Industrial Crops and Products, 80: 141-147.

Yu, X; Li, Q; Sun, D; Dong, X and Wang, T (2015). Determination of the peroxide value of edible oils by FTIR spectroscopy using polyethylene films. Analytical Methods, 7(5): 1727-1731.

Zeb, A and Murkovic, M (2013). Pro-oxidant effects of $\beta$-carotene during thermal oxidation of edible oils. J. Amer. Oil Chem. Soc., 90 (6): 881-889. 